\title{
Effects of association value of trigrams and ITI on short-term memory
}

FRANK C. LEEMING, DEPARTMENT OF PSYCHOLOGY, MEMPHIS STATE UNIVERSITY, Memphis, Tenn. 38III

The variables of a 2 by 2 factorial design were association value of trigram stimuli $(<25 \%$ and $>75 \%)$ and ITI $(6 \mathrm{sec}$ and $60 \mathrm{sec})$. With 40 Ss per group, both association value and ITI produced highly significant differences in the total number of correct responses. Proactive interference effects over the first three trials were analyzed separately for the high and the low association value items. It was found that increasing ITI reduced PI with the high association value items but not with the low association value items.

Variations in level of performance on a short-term memory task as a function of the serial position of the item has received considerable attention. One of the most reliable serial position effects is the very rapid decrement in performance which occurs over the first two or three items. This effect has frequently been attributed to proactive interference (PI) in which the early items in the list interfere with performance on the later items. This interpretation has been supported by the finding of Loess \& Waugh (1967) that the performance decrement could be reduced and finally completely eliminated by increasing the intertrial interval from the usual $10-15 \mathrm{sec}$ to a maximum of $300 \mathrm{sec}$. In both of the experiments reported by Loess and Waugh, the items to be recalled were word-triads composed of three-letter words. It seems likely that the effects of changing the ITI should be influenced by the nature of the material to be recalled. Therefore, the experiment reported here varied the association value of trigram (CCC) stimuli as well as the ITI.

Method. The Ss were 160 student volunteers from introductory psychology classes at Memphis State University. Extra credit was given in the individual classes for participation in the experiment. All Ss were naive to psychology experiments.

Two groups of 10 trigrams each were selected from Witmer's (Underwood \& Schulz, 1960) list of CCCs scaled for association value. One group contained items having association values of less than $25 \%$; the other group greater than $75 \%$. Each group contained 17 different letters, and within each group 13 letters appeared twice and four letters appeared once. The trigrams in each group were arranged in 10 different orders in such a way that each item appeared once in each serial position.

Ten 3-digit numbers were also selected. Each digit appeared an approximately equal number of times. and the items were ordered so as to minimize the similarity between the numbers in any portion of the list. All Ss saw the same numbers arranged in the same sequence.

The CCCs and numbers plus the words REST and READY and a row of five asterisks were printed on acetate matte, photocopied, and inserted in 2 in. $x 2$ in. slide mounts. These materials were projected on the back of an 8 in. $x 8$ in. screen by means of a Kodak Carousel slide projector. The screen was mourted in a 24 in. $x 34$ in. board painted flat black which served to separate E from $S$. The projector was programmed by means of a Gerbrands variable interval timer. With this apparatus, the time between the end of one slide and the start of the next was approximately $0.5 \mathrm{sec}$. A metronome set to produce 60 beats per min was used to pace S's counting during the retention interval.

The general format of the Peterson \& Peterson (1959) procedure was followed. A trial began with the presentation of the word REST for the appropriate time. For half of the Ss the rest period was $6 \mathrm{sec}$, for the other half it was $60 \mathrm{sec}$. During each rest period, $S$ was asked to work as many as possible of the simple arithmetic problems printed on a sheet which he reccived at the start of the experiment. It was hoped that this procedure would minimize Ss thinking about earlier stimulus items during the rest period. The rest period was followed by the word READY for 2 see. The stimulus item, which $S$ was required to spell aloud, then appeared for 1 sec. A 3-digit number was ther presented for 1 see followed by a blank slide for the rentainder of the 15 -sec retention interval. The $S$ read the number aloud and innediately began counting backward by threes from this number. (ounting was paced by the beating of the metronome, and continued until the row of five asterisks appeared. This cue for $S$ to recall the most recently seen trigram remained on the screen for $10 \mathrm{sec}$. The word REST then reappeared to start the next trial.

The result of this procedure was a 2 by 2 factorial design having as experimental variables association value $(<25 \%$ and $>75 \%)$ and rest or intertrial interval $(6 \mathrm{sec}$ and $60 \mathrm{sec})$. A total of $40 \mathrm{Ss}$ was tested under each treatment combination. Within each treatment combination, an equal number of Ss was tested with each trigram order.

Results. The results of this experiment are summarized in Fig. 1 which presents the number of correct responses at each serial position as a function of association value and rest interval. An analysis of variance carried out on the total number of correct responses per $\mathrm{S}$ showed the effects of both association value and rest interval to be significant $(\mathrm{F}=20.62, \mathrm{df}=1 / 156, \mathrm{p}<.00 \mathrm{I}$ and $\mathrm{F}=17.13, \mathrm{df}=1 / 156, \mathrm{p}<.001$, respectively).

The main interest of this experiment was to analyze the PI effects during the early trials. To accomplish this, the number of Ss going from correct on Trial 1 to incorrect on Trial 2 was analyzed as a function of the ITI. Separate analyses were carried out on the high and low association value items. For the high association value items, this difference was significant $(\mathrm{z}=2.21, \mathrm{p}$ $=.01$ ), indicating that there was less PI with the longer ITI. However, with the low association value, the difference between the long and short ITI groups did not approach significance $(z=$ .18).

A similar analysis was carried out on the number of Ss going from correct on Trial 1 to incorrect on Trial 3. Again, with the high association value items the difference was significant $(z=$ $1.82, \mathrm{p}=.03)$ while with the low association value items, the difference failed to approach significance $(\mathrm{z}=.47)$.

The influence of the experimental variables on PI may be seen in Fig. 1. With the high association value items there is clearly a

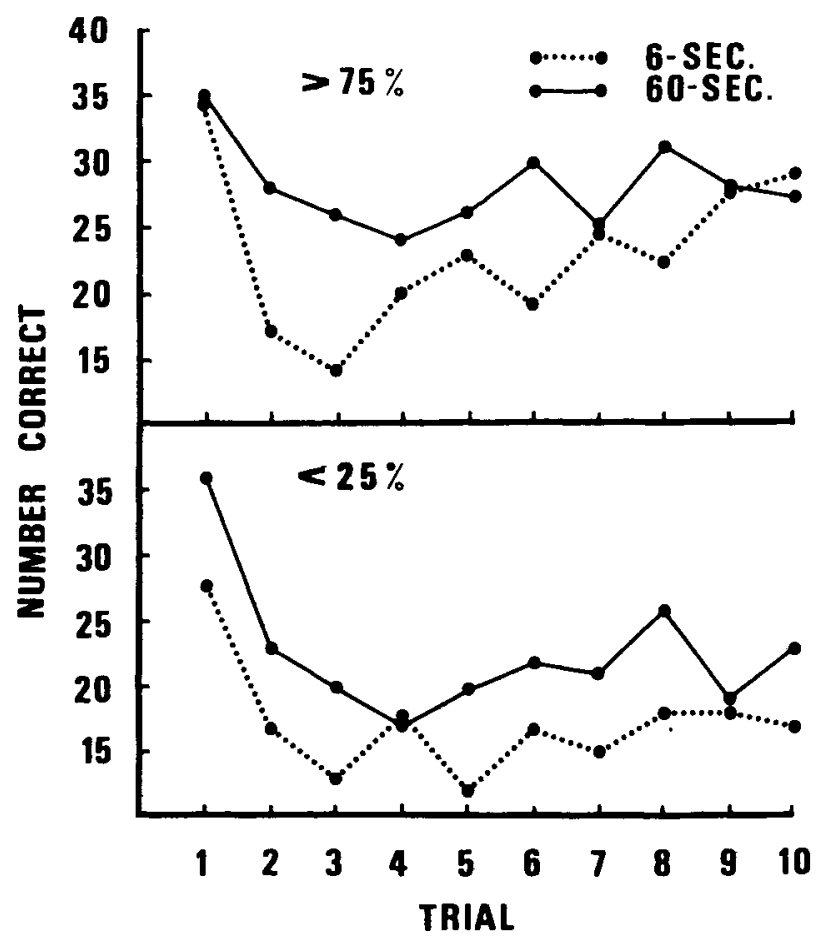

Fig. 1. Retention of single trigrams as a function of association value. ITI, and trial. 
divergence between the 6 and 60 -sec ITI groups over the first three trials. On the other hand, with the low association value items, the functions representing the two groups are almost parallel over the first three trials.

Discussion. The results of this experinent confirm the finding by Loess \& Waugh (1967) that PI in short-term memory is reduced by an increase in ITI. It was also demonstrated that the influence of ITI on PI is greater with higher association value trigrams. The length of the ITI was not found to influence PI when the stimuli were trigrams having association values of $<25 \%$. Loess and Waugh used ITIs which were as long as $300 \mathrm{sec}$, while in the present experiment the longest ITI was $60 \mathrm{sec}$. It seems reasonable to assume that if a longer ITI had been used in the present experiment, some effect would have been observed with the lower association value items.

REFERENCES

LOESS, H., \& WAUGH, N. C. Short-term memory and intertrial interval. $J$. verbal Learn. verbal Behav., 1967, 6, 455460.

PETERSON, L. R., \& PETERSON, M. J. Short-term retention of individual verbal items. J. exp. Psychol., 1959, 58, 193-198.

UNDERWOOD, B. J., \& SCHULZ, R. W. Meaningfulness and verbal learning. Philadelphia: Ljppincott, 1960. 